\title{
Study of the Influence of an Air- Entraining Agent on the Rheology of Motars
}

\author{
Nadia Tebbal* ${ }^{1}$, Zine El Abidine Rahmouni ${ }^{1}$, Lamis Rabiaa Chadi ${ }^{2}$ \\ $*{ }^{1}$ Institute of Technical Urban Management, University of M'sila Algeria \\ ${ }^{1,2}$ Geomaterials Development Laboratory, Civil Engineering Department, M'sila University, M'sila, Algeria.
}

\begin{abstract}
The objective of this study is to analyze the effect of the air entrainment on the fresh rheological properties as well as on the compressive mechanical resistances of the mortars. The hardened concrete contains a certain amount of randomly spread air, coming either from a drive during kneading or from the evaporation of the mixing water. The air quantity is in the order of $201 / \mathrm{m}^{3}$, ie $2 \%$ of the volume. However, the presence of a large volume of air bubbles causes the mechanical resistances to fall in compression. On the other hand, the use of air entrainment could improve the rheological properties of fresh concrete.

Experimental studies have been carried out to study the effect of air entrainment on compressive strength, density and ingredients of fresh concrete mix. During all the study, water cement ratio $(\mathrm{w} / \mathrm{c})$ was maintained constant at 0.5 . The results have shown substantial decreasing in water and mortar density followed with decreasing in compressive strength of mortar. The results of this study has given more promising to use it as a guide for mortar mix design to choose the most appropriate concrete mix design economically.
\end{abstract}

\section{Introduction}

Air entrained concrete consider one of the important discovery made in concrete technology. It is well-known that AEA can improve the workability of the fresh concrete and improve the frost resistance and permeability of the hardened concrete.

Therefore, it has a practical and theoretical significance to research the influence of air entraining agent on mortar and concrete rheological properties and bubble characteristic parameters.

Y. Jiang, Z., 2006, studied the research of air entraining agent on concrete rheological properties and bubble characteristic parameters effect, it found that air entraining agent decreased concrete compressive strength, slightly added concrete flexural strength, and folding compression ratio increased significantly.

Many researches showed that the addition of airentraining agent increased the air content up to a saturation level, above which no further increase in air content was observed. With increasing air content, the yield stress increased and the plastic viscosity decreased. (L.J. Struble, 2004).

Frost durability is very important for concrete structures exposed to low temperature because concrete is a porous material that contains water in various forms. To protect the concrete against freezing, the air content and the spacing factor must be taken into account, since it is possible to produce concrete with an air content that meets the specifications but whose spacing factor is not sufficient to protect the concrete from frost (F.Saucier .1991).

The deterioration would not appear in the concrete after a single period of freezing, but it would be the result of progressive damage due to the succession of a greater or less number of freeze-thaw cycles (Carles-Gibergues A. 1992). The use of air entraining aids facilitates the placement of concrete and protects them from frost (Lianxiang Du, 2005). But this use is effective insofar as the bubbles that are added improve the network of air bubbles. This appears to be possible only if the dose of AEA added is quite high (M .Pigeon, 1990), if not there is a risk of only $1 \%$ to $2 \%$ of air, which is not enough to guarantee an improvement of the network. This increase could just as well be due to the fluidification of the mixture by the addition of water with the AEA.

Generally this fluidization mainly results in large bubbles which are liable to be lost thereafter [Pigeon M, 1987]. Similarly, recent studies in the field such as Nicola Pitrov's (P.Nikola, 2003), have found that the absence of AEA in concrete exposed to de-icing effects causes a rather remarkable decrease in compressive strength, elasticity.

The objective of this paper is to present the results of a research is to formulate a series of air entraining agent dosages incorporated into the mortar mixtures during mixing in order to develop a formulation that provides the mortar with a better durability over time and protecting it in particular at repeated cycles of gels. These formulations of mortars consist in also having a better rheological behavior with respect to the 
maneuverability without having a significant loss of resistance which exceeds the standards.

\section{Experimental program}

\subsection{Characteristics of the materials used}

Cement: This is a Portland cement (CEM II 42.5) has a Blaine specific surface area of $3585 \mathrm{~cm}^{2} / \mathrm{g}$ and a density of 3.2. Chemical and mineralogical composition is given by Bogue's formulas (Table 1).

Sand: The binary sand mixtures aggregates used in this study were SD (dune sand) and CS (crushed sand). The characteristics of binary sand mixtures are given in Table 2. The dune sand used with particles ranging from 0.08 $\mathrm{mm}$ to $5 \mathrm{~mm}$ in size. This natural sand was taken from Boussâada, Algeria. The granulometric study is performed according to standard NF P18-304 after the treatment process, allows to eliminate a significant portion of clay minerals. In this study the manufactured fine aggregate used is crushed sand generated by the quarry waste.

An improvement of porosity of the binary mixture (crushed and dune sands) and correct the variation of the granulometric composition (particle sizes) using $1 / 3$ of crushed sand blend.

The adjuvant: used is an air entraining agent (MEDA AIR). It is a solution of $\mathrm{pH}=7-8$ and a density of $1 \pm$ 0.01 , with ions chlores $\leq 1 \%$. Its normal use scale is fixed by the manufacturer's recommendation of 0.01 to $0.1 \%$ of the cement weight. The percentage of the chemical admixture used was $0.08 \%$ by weight of cement for all mixes.

In this study we used the super plasticizer named (MEDAFLOW 30); it was obtained according to NFP 18333 and NFP 18336.

Table 1: Chemical and mineralogical composition of cement

\begin{tabular}{|c|c|c|}
\hline & $\begin{array}{c}\text { Compositions } \\
(\%)\end{array}$ & $\begin{array}{c}\text { Cement } \\
(\%)\end{array}$ \\
\hline & $\mathrm{SiO}_{2}$ & 18.48 \\
& $\mathrm{CaO}$ & 61.04 \\
& $\mathrm{Al}_{2} \mathrm{O}_{3}$ & 4.51 \\
& $\mathrm{Fe}_{2} \mathrm{O}_{3}$ & 3.21 \\
$\mathrm{MgO}^{\text {Chemical }}$ & $\mathrm{SO}_{3}$ & 2.16 \\
compositions & $\mathrm{MnO}$ & 2.18 \\
& $\mathrm{Na}_{2} \mathrm{O}$ & 0.13 \\
& $\mathrm{~K}_{2} \mathrm{O}$ & 0.56 \\
& $\mathrm{Cl}^{-}$ & \\
\hline \multirow{4}{*}{ Mineralogical } & $\mathrm{C}_{3} \mathrm{~S}$ & 57 \\
& $\mathrm{C}_{2} \mathrm{~S}$ & 18 \\
& $\mathrm{C}_{3} \mathrm{~A}$ & 07 \\
& $\mathrm{C}_{4} \mathrm{AF}$ & 11 \\
& $\mathrm{Gypsum}$ & 15 \\
\hline
\end{tabular}

\subsection{Experimental procedure}

\subsubsection{Formulation of Mortar}

Fresh mortar mixes were prepared in modified laboratory mixer. Mixtures were prepared from dry aggregates. Cement and sand were dosed by weight, water and chemical admixtures were added by volume.

The mortar formulation tested is performed by formulating's method mortar of the Skramataiv .

The same mixing procedure was used for all mortars:

1. Place the cement and water in the mixer bowl.

2. Mix cement and water 30 seconds min.

3. Add sand 30 second speed min.

4. Mix cement and sand and water 30 seconds fast speeds.

5. Leave to stand for 1 minute 30 seconds.

6. Mix for 1 minute fast speed.

In the case of the use of adjuvants, the latter is diluted in the mixing water. The concrete specimens are preserved in their mould in wet place $(20 \circ \mathrm{C}, 95 \% \mathrm{HR})$ during 24 hours. Then they undergo immersed in the potable water tap. The physical, mechanical characteristics of the concrete are compared.

In order to investigate the influence of an airentraining agent on the rheology of mortars, prisms samples with the dimensions of $7 \times 7 \times 14 \mathrm{~cm}$, are produced. After 28 days curing conditions, the samples were used for the determination of the compressive strength.

Freezing thaw test: Six specimens for each type of mortar were tested according to freezing-thawing NF $\mathrm{P}$ 18-425 standard. One specimen of each type of mortar was stored at $20{ }^{\circ} \mathrm{C}$ and $45-50 \%$ relative humidity for comparison.

It should be noted that the calculation of the composition of the concrete was made by the «Absolute "elaborated by Professor B. Scramtaïv (A.KOMAR 1978). Table 2 present the complete formulation of the 02 mortar mixes for cement dosages of $400 \mathrm{~kg} / \mathrm{m}^{3}$ and for $\mathrm{W} / \mathrm{C}=0.5$, with AEA determinations based on the weight of the cement. The workability was measured by the slump test using the Abrams cone in accordance with the standard NF P 18-451, which makes it possible to make a connection between the dosage of AEA and the maneuverability.

Table 2: The mortar composition with AEA

\begin{tabular}{|c|c|c|c|}
\hline Mix (g) & M0 & M1 & M2 \\
\hline AEA & - & \multicolumn{3}{|c|}{0.36} \\
\hline Cement (C) & \multicolumn{3}{|c|}{450} \\
\hline Sand dune ( SD ) & \multicolumn{3}{|c|}{450} \\
\hline Crush sand ( CS ) & \multicolumn{3}{|c|}{900} \\
\hline Water /Cement ( W/C ) & \multicolumn{3}{|c|}{0.50} \\
\hline Super plasticizer & - & - & 4.50 \\
\hline
\end{tabular}




\section{Results and discussions}

\section{1 Behavior of fresh concrete}

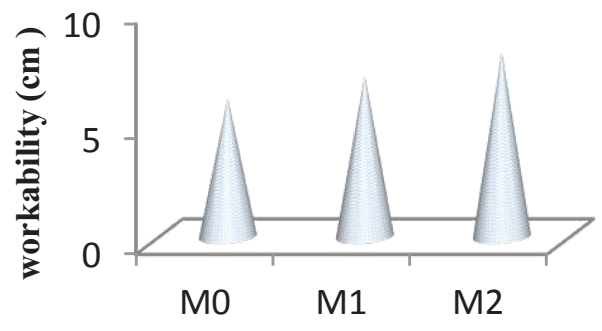

Type of mortar

Fig. 1. Workability of mortars

Workability is an essential quality of mortar; it can be defined as the ease of application of the mortar.

Based on the experimental results presented in Fig. 1 , the incorporation of adjuvant affects the workability of mortar positively. Indeed, an air- entraining agent or super plasticizer enhances the handling by making a more workable mix of a plastic mortar rheological behavior.

From Fig. 1, it can be observed that all the mortar mixtures with adjuvant gave better workability compared to the control mix at the values ranging from $6 \mathrm{~cm}$ slump for the first one and 7 to $8.5 \mathrm{~cm}$ slump for the latter. This is in agreement with other results on the subject found previously where there was an improved fluidity of mortars at fresh state of these types with incorporation of blends (Du.Lianxiang, 2005).

\subsection{Effect of air entrainment on density of mortar in mortar mix}

Figure 2 illustrate the relationship between type mortar and density of concrete.

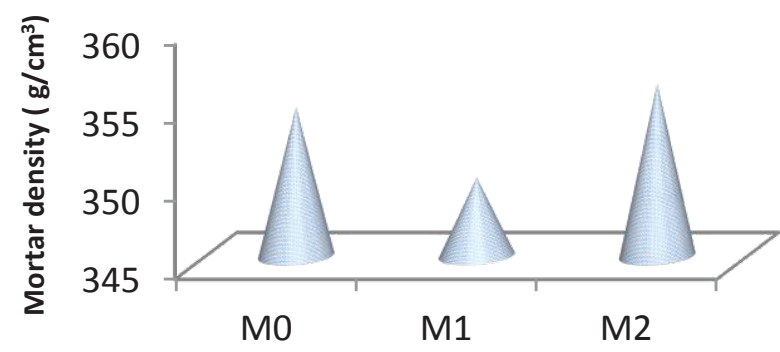

Type of mortar

Fig. 2. Effect of air entrainment on density of concrete in concrete mix
Density of non-air entrained mortar is $354.5 \mathrm{~g} / \mathrm{cm}^{3}$ while air entrained cement mortar from 350 to $356 \mathrm{~g} / \mathrm{cm}^{3}$ (Fig.2). This confirms the relationship that the bulk density of the mortar is inversely proportional to the amount of air. The $\left(\mathrm{M}_{1}\right)$ cement mortar had the lowest bulk density among with air entrained mortars. The highest bulk density has been determined for mortars with Portland cement both non- air entrained and air entrained $\left(\mathrm{M}_{0}, \mathrm{M}_{2}\right)$.

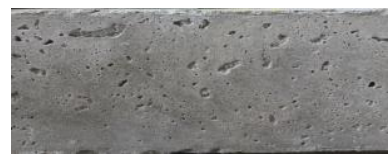

( a )

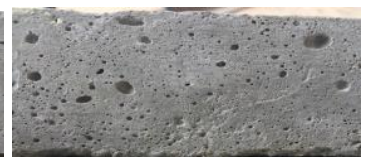

(b)
Fig . 3. Mortars with and without AEA

\subsection{Compressive strength}

Figure 4 shows the evolution of the compressive strength of concretes based on an AEA.

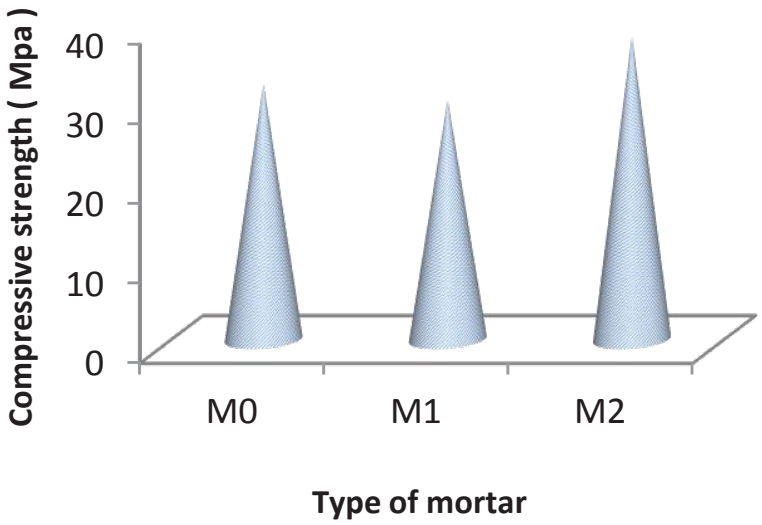

Fig. 4. Influence of the AEA on resistance to compression at the age of 28 days

The results of Fig. 4, it can be concluded that the mortars $\left(\mathrm{M}_{0}\right.$ and $\left.\mathrm{M}_{1}\right)$ has resistances which evolve slightly and which tend towards stable values, whereas for mortar with AEA there is a drop in resistance which depends on the air entrained. The compressive strength of mortar decreases for tests carried out on mortars with $\mathrm{E} / \mathrm{C}$ ratios of 0.5 .

The amount of occluded air measured in the case of these concretes or mortars varies between 1 and $2.8 \%$. It is realized that $1 \%$ of air, occupying the same volume as ten liters of water, similarly reduces the compressive strength, it is evident that the air occluded in concrete must always be measured and taken Account (Baron \& Ollivier, 1996).

One of the most important effects is certainly the influence of the voids provoked by the air occluded on 
the compressive strength of the mortar. It is known that the strength of the mortar is a direct function of its compactness and the occluded air voids affect the compressive strength in the same way as voids of any other origin.

\subsection{Freezing and thawing}

Figs. 5 show the evolution of the compressive strength of mortars based - AEA exposed to freeze-thaw cycles.

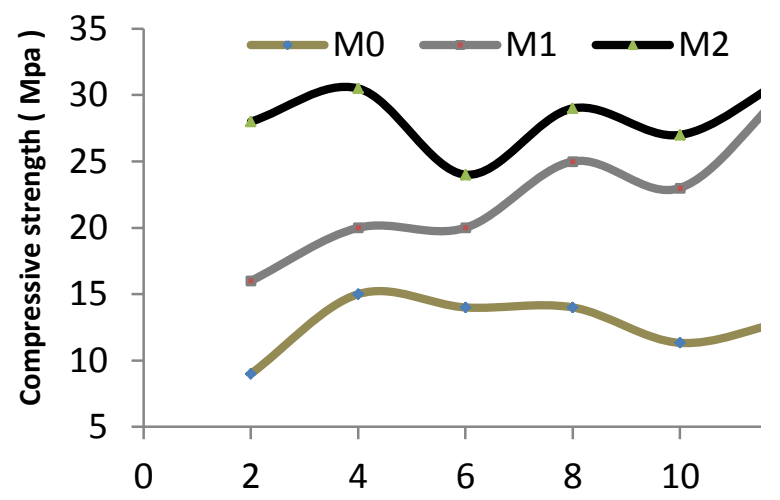

Fig. 5. Compressive strength of the mortar exposed to freezethaw cycles

Through the results of Fig. 5, it can be concluded that the mortars without an air-entraining agent have resistances which evolve slightly and which tend towards stable values, whereas for mortars with AEA there is a decrease in resistance which depends on the number of cycles. This reduction in strength becomes quite important when mortars are exposed to severe freezethaw cycles, which is consistent with the results of Nicola Pitrov .

\section{Conclusions}

It has been studied the effect of air entrained on the rheology of mortars. It was noticed that the air bubbles which generated by using either special type of cement or by using an air entrainment agent distributed in the entire mass of the mortar acting as flexible ball bearings. The conclusion of this study can be summarized as following.

$>\quad$ The air entrainment can reduce the ingredients of mortar without any effect in the workability of the mortar mix which mean more economical mortar mix can be achieved by using air entrainment agent whoever decreasing of concrete compressive strength by increasing of air entrainment should be considered.

$>$ The reduction of density due to the increasing of air entrainment in the mortar mix result in a lower heat of hydration in mass mortar.

\section{References}

1. Y. Jiang, Z. Xu, Engineering performance of polycarboxylate based air entraining agent, J. of South.Univ (Natural Science Edition), vol. 36, no. 4, pp. 568-571, 2006.

2. L.J. Struble, Leslie J. Struble and Qingye Jiang. Effects of Air Entrainment on Rheology ACI Mater J /November-December 2004

3. F.Saucier et al., Air-void Stability, Part V, General Analysis and performance Index. ACI Mater J, Vol. 88, No.1, pp 25-36 (Jan.-Feb. 1991).

4. M.A., Carles-Gibergues, A., La durabilité des bétons face à l'alcali-réaction, La durabilité des bétons ed. by J. Baron, J-P. Ollivier, Presses Ponts et Chaussées.1992.

5. M.PIGEON, F. SAUCIER et P. PLANTE; «Airvoid stabiliy ». Part Iv: Retempering, ACI Matér J, pp 252-259, (May/June 1990).

6. M.PIGEON, F.SAUCIER et P. PLANTE, Production et stabilité du réseau de bulles d'air entraîné dans le béton». Rapport soumis au Conseil de Recherche en Sciences Naturelles et en Génie et à la Compagnie VERREAULT-FRONTENAC, (Avril 1987).

7. P.Nikola ; effets combinés de différents facteurs sur l'expansion des bétons causée par la formation différée de l'ettringite. thèse de doctorat, Sherbrooke (Québec), pp 55-57, Canada (Avril 2003).

8. A.KOMAR 1978 .Matériaux et éléments de construction ", Version française ; Editions Mir. Moscou, 540, (1978).

9. Du.Lianxiang, Mechanisms of air entrainment in concrete, Cem and Conc Research. Vol. 35, Issue 8, August 2005, Pages 1463-1471.

10. J. Baron, et Ollivier, Les bétons bases et données pour leur formulation. Edition Eyrolles, Paris.1996. 